\title{
Contrastando Opiniões acerca da Adoção de Crianças por Casais Hétero e Homossexuais
}

\author{
Leogildo Alves Freires ${ }^{1}$ \\ ${ }^{1}$ Universidade Federal de Alagoas, AL, Brasil. \\ Gleidson Diego Lopes Loureto ${ }^{2}$ \\ ${ }^{2}$ Centro Universitário de Patos, $P B$, Brasil.
}

\author{
Alessandro Teixeira Rezende ${ }^{3}$ \\ ${ }^{3}$ Faculdade de Integração do Sertão, PE, Brasil. \\ Ana Karla da Silva Soares ${ }^{4}$ \\ ${ }^{4}$ Universidade Federal do Mato Grosso do Sul, MS, Brasil.
}

\begin{abstract}
Resumo: Apesar de haver um contexto aparentemente favorável e de crescente reconhecimento pelo sistema jurídico brasileiro referente à adoção por casais homossexuais, constitui-se em equívoco afirmar que a manifestação do preconceito e da discriminação frente aos homossexuais esteja reduzindo no Brasil. Tendo em vista tal cenário, o presente estudo objetivou contrastar as opiniões de uma amostra brasileira acerca da adoção por casais homossexuais, frente a um arranjo heterossexual estéril. Para tanto, contou-se com uma amostra da população geral composta por 484 adultos brasileiros (média de idade $=26,6 ; \mathrm{DP}=8,31,62,0 \%$ feminino), que responderam um questionário sociodemográfico e a duas questões abertas contendo dois cenários de adoção, compostos por casais heterossexuais estéreis e casais homossexuais. A partir da análise de Classificação Hierárquica Descendente, realizada no software Iramuteq, identificou-se a presença de cinco classes no cenário de adoção por casais heterossexuais estéreis (agravantes, desenvolvimento normal, educação, solidariedade e responsabilidade) e no cenário de adoção por casais homossexuais (preconceito, oposição, contexto de favorabilidade, lar amoroso e desenvolvimento infantil). Os resultados apontaram diferentes padrões de aceitação/oposição em função do tipo de configuração parental da família adotante. Tais resultados são discutidos considerando as implicações de normas sociais de padrão hetero-cis-normativo, ressaltando-se a necessidade de dispositivos jurídicos, em forma de lei, que amparem os direitos civis de casais homossexuais no Brasil.
\end{abstract}

Palavras-chave: Adoção, Criança, Homoparentalidade, Levantamentos de opinião.

\section{Contrasting Opinions about Children Adoption by Heterosexual and Homosexual Couples}

\begin{abstract}
Despite the seemingly favorable context and growing recognition regarding adoption by same-sex couples by the Brazilian legal system, these factors do not allow us to rightfully infer that prejudice and discrimination against homosexuals are decreasing in this country. Considering that, this study aimed to contrast opinions about adoption by infertile heterosexual and same-sex couples in a sample of 484 Brazilian adults (mean age $=26.6$; $\mathrm{SD}=8.31,62.0 \%$ women). Data were collected by means of a demographic questionnaire and two semi-structured questions, presenting adoption in two different scenarios: by either homosexual or infertile heterosexual couples. From a descending hierarchical classification analysis performed using the Iramuteq software, five classes for the aforementioned scenarios were identified: infertile heterosexual (aggravating factors, normal development, education, solidarity, and responsibility) and homosexual couples (prejudice, opposition, favorable environment, loving home, and child development). The results indicate different agreement/disagreement patterns regarding the adopting couple parental configuration, whereby same-sex adoption implied an opposition response pattern whereas infertile heterosexual adoption resulted in more evident favorable positions. These results
\end{abstract}


are discussed in the light of the implications arising from the social norms of heterosexist and cissexist systems, highlighting the importance of legal instruments such as governmental laws that guarantee the civil rights of the homosexual population in Brazil.

Keywords: Adoption, Children, Same-sex parenting, Opinion surveys.

\title{
Contraste de Opiniones sobre la Adopción de Niños por Parejas Hetero y Homosexuales
}

\begin{abstract}
Resumen: A pesar de un contexto aparentemente favorable y de creciente reconocimiento por el sistema jurídico brasileño en relación a la adopción por parejas homosexuales, es una equivocación decir que la manifestación del prejuicio y de la discriminación hacia los homosexuales se está reduciendo en Brasil. El presente estudio tuvo objetivo contrastar las opiniones de una muestra de la población brasileña con respecto a la adopción de niños por parejas homosexuales cuando comparadas con parejas heterosexuales estériles. Para ello, la muestra fue de 484 brasileños adultos (edad promedia de 26,6; $\mathrm{DE}=8,31 ; 62,0 \%$ mujeres), que contestaron a preguntas sociodemográficas y a dos preguntas abiertas sobre dos escenarios de adopción: un con parejas heterosexuales estériles y otro con parejas homosexuales. A partir del análisis de Clasificación Jerárquica Descendente (realizada por el software Iramuteq), se identificó cinco clases para cada escenario: parejas estériles (agravantes, desarrollo normal, educación, solidaridad y responsabilidad) y parejas homosexuales (prejuicio, oposición, contexto de favorabilidad, hogar amoroso y desarrollo infantil). Los resultados indican formas diferentes de aceptación/oposición según el tipo de configuración de las parejas adoptantes. Estos hallazgos son discutidos teniendo en cuenta las implicaciones de normas sociales de estilo hetero-cisnormativo, sugiriendo la necesidad de aparatos jurídicos, en forma de leyes, que soporten los derechos civiles de parejas homosexuales en Brasil.
\end{abstract}

Palabras clave: Adopción, Niño, Familia homoparental, Opinión.

Debates gerais relacionados aos grupos sexuais minorizados estão intrinsecamente ligados às concepções em torno do conceito tradicional de família e repercutem em diversas esferas, como as sociais e institucionais, gerando implicações práticas para a vida de tais grupos, como no âmbito da adoção homoparental (Takács, Szalma, \& Bartus, 2016), isto é, quando o casal adotante é constituído por homossexuais (Patterson, 2006) ou por apenas um indivíduo que se declara homossexual (Santos, Araújo, Negreiros, \& Cerqueira-Santos, 2018). De fato, a oposição aos direitos parentais de casais compostos por pessoas do mesmo gênero está associada à resistência de ampliação do conceito tradicional de família (Takács \& Szalma, 2014) que, por sua vez, preserva mitos e falsas crenças de que há consequências prejudiciais ao desenvolvimento de crianças socializadas fora de um contexto familiar denominado nuclear (Golombok, 2015).
Ressalta-se que tais debates, do ponto de vista prático, criaram demandas sociais em diversas áreas (Machin, 2016). Especificamente no contexto brasileiro, o tema da adoção homoparental permaneceu avessa ao Poder Legislativo, existindo tendência contrária ao reconhecimento da condição de entidade familiar de pessoas do mesmo gênero (Azevedo, 2011), implicando, assim, em imprecisões quanto a assegurar a efetivação dos direitos de tais arranjos familiares (Mello, 2006). Dessa forma, diante da ausência de legislação expressa, tem cabido ao Poder Judiciário julgar os casos de adoção homoafetiva (Baranoski, 2016). Nesse sentido, no Brasil, importantes avanços foram observados no que tange a um maior reconhecimento de direitos dos grupos sexuais minorizados. Um exemplo desse reconhecimento consiste na decisão do Supremo Tribunal Federal (STF), de 2011, que considerou a conjugalidade homossexual como 
regime jurídico da união estável, garantindo direitos formais aos casais homossexuais de todo o país (Pereira, Torres, Falcão, \& Pereira, 2013). Em 2015, o mesmo tribunal ratifica o direito legal à adoção homoparental (Fiuza, 2015).

No entanto, apesar desse contexto aparentemente favorável e de crescente reconhecimento da temática pelo sistema jurídico brasileiro, constitui um equívoco afirmar que a manifestação do preconceito (atitudes negativas direcionada a um indivíduo ou grupo) e da discriminação (expressão comportamental do preconceito) frente aos homossexuais estejam reduzindo no Brasil, pois, apesar de a homossexualidade ser discutida abertamente na mídia e na literatura científica, ainda é considerada uma "anormalidade" (Mott, 2006). Paralelamente a essa discussão, é importante considerar o impacto dos impedimentos legais vivenciados pelos homossexuais ao longo da história, como a ausência dos direitos a união estável e adoção, bem como da expressão de violência direcionado a esse grupo (Araújo, Oliveira, Sousa \& Castanha, 2007; Falcão, 2004).

Efetivamente, embora diversos estudos apontem que existem mais similaridades do que diferenças entre casais heterossexuais e homossexuais, sejam aqueles formados por duas mulheres ou por dois homens (Gato \& Fontaine, 2014), o preconceito ainda existe em diversas formas, como a concepção de que pessoas do mesmo gênero não apresentam competência parental (Tasker, 2013), sobretudo no caso dos casais gays (Gates, Badgett, Macomber, \& Chambers, 2007). É comum a crença de que os homens, quando comparados às mulheres, não possuem as qualidades necessárias para cuidar de crianças (Aboim, 2007). Além disso, quando buscam o exercício da parentalidade, os homens transgridem as expectativas relacionadas ao gênero masculino (Berkowitz \& Marsiglio, 2007). Ademais, o cenário de práticas discriminatórias no país contra a população LGBT ratifica tal situação. No ano de 2015, registrou-se um crime de ódio a cada 27 horas no Brasil, sendo as travestis e transexuais as mais vitimizadas, totalizando 318 assassinatos (Grupo Gay da Bahia, 2016). Ademais, os dados mostraram um crescimento de $30 \%$ nos assassinatos da população LGBT entre os anos de 2016 e 2017, registrando-se nesse último um total de 455 assassinatos, em uma proporção de um crime de ódio a cada 19 horas (Grupo Gay da Bahia, 2017).

Desde os anos 1980, atos de violência contra a população LGBT no Brasil constituem pauta central do ativismo LGBT brasileiro (Ramos \& Carrara, 2006).
Entretanto, na década de 1990, além desse aspecto, observou-se maior proeminência de reivindicação de direitos direcionados, sobretudo, ao reconhecimento da conjugalidade entre pessoas do mesmo gênero e, por extensão, da possibilidade de adoção (Uziel, 2007). Assim, percebe-se que o desejo do exercício da parentalidade por parte de homossexuais no Brasil não é reivindicação recente. Convergente a essa discussão, estudos na literatura se debruçaram para desmistificar a concepção enviesada de que os homossexuais não manifestam desejo parental (Freires, 2015; Gato \& Fontaine, 2014).

Assim, além do importante fator da violência contra esses sujeitos, a comunidade LGBT busca a superação das desvantagens jurídicas das quais também é vítima (Daniliauskas, 2011). Por exemplo, em estudo conduzido no contexto estadunidense por Brodzinsky, Patterson e Vaziri (2002) com agências públicas e privadas de adoção $(\mathrm{N}=214)$, identificou-se que embora $63 \%$ das agências aceitassem o cadastro de casais homossexuais, apenas $38 \%$ delas registraram pelo menos um caso de adoção homoparental no período de dois anos. Os autores verificaram, também, que tais resultados refletiam os valores religiosos das instituições (Appell, 2001).

Nesse sentido, para além do estudo dos efeitos de variáveis individuais (Whitley, 2001), afiliação religiosa (Scheepers, Te Grotenhuis, \& van der Slik, 2002) ou teorias psicológicas (Altemeyer, 1998) nas atitudes frente às demandas da comunidade LGBT, algumas investigações têm considerado o impacto da existência de legislação que ampare os direitos de homossexuais. De forma concreta, dados transculturais de 2003 oriundos de 25 países europeus $(\mathrm{N}>15,000)$ mostraram que as atitudes quanto à adoção homoparental variam de acordo com a legislação nacional vigente, isto é, maiores níveis de apoio da opinião pública eram mais característicos de países nos quais tais leis eram vigentes ou se encontravam em pleno trâmite de desenvolvimento (EOS Gallup Europe, 2003). Na mesma direção, o estudo realizado por van den Akker, van der Ploeg e Scheepers (2013), também no contexto europeu, com dados de 20 países do European Social Survey ( $=142.464)$, apontou que menores índices de desaprovação da homossexualidade foram identificados nos países em que havia legislação permitindo tanto a conjugalidade quanto a adoção por pares do mesmo gênero.

Nesse sentido, tendo em vista a inexistência até o presente momento de legislação específica, no Brasil, sobre a temática supracitada, associada às condições 
de discriminação da população LGBT em diversos contextos, como dos sistemas legal e de saúde (Power et al., 2010), e à contínua estigmatização em razão da condição de grupo sexual minorizado (Frost \& Meyer, 2009; Lomando, Wagner, \& Gonçalves, 2011), o presente estudo objetivou contrastar as opiniões de uma amostra brasileira acerca da adoção por casais heterossexuais estéreis e casais homossexuais. Para tanto, nesta ocasião, analisaram-se dados provenientes do mês de julho de 2014 (Freires, 2015), momento em que o STF ainda não tinha se pronunciado expressamente acerca do reconhecimento do direito à adoção por parte de casais homossexuais. Ademais, para fins comparativos, além da opinião sobre a adoção por casais homossexuais, considerou-se também a opinião sobre a adoção por casais heterossexuais estéreis, impossibilitados biologicamente de gerar filhos(as). Tal procedimento possibilitou contrastar as respostas dos respondentes em ambas as condições, possibilitando a compreensão de nuances desse fenômeno.

\section{Método}

\section{Participantes}

Para a realização deste estudo, de natureza transversal (do tipo ex post facto), contou-se com 484 participantes que foram contactados por meio da internet e responderam ao questionário que estava disponível apenas em formato on-line. Eles tinham idades entre 18 e 58 anos ( $M=26,6 ; \mathrm{DP}=8,31)$, sendo a maioria do gênero feminino $(62,0 \%)$, heterossexual $(70,2 \%)$, estudantes universitários (i.e., sujeitos matriculados em cursos em nível de graduação, ensino superior; 46,1\%) e católicos $(40,7 \%)$. Tratou-se de amostra de conveniência (não probabilística).

\section{Instrumentos}

Os participantes responderam um questionário sociodemográfico (escolaridade, gênero, orientação sexual, importância da religião e idade) e a duas questões abertas: a) Qual a sua opinião acerca de adoção de crianças por casais heterossexuais que não podem ter filhos biologicamente? Justifique sua resposta apontando elementos que têm uma relação importante com tal situação; e b) Agora mudando a configuração familiar, responda-nos qual a sua opinião sobre adoção de crianças por casais homossexuais? Justifique sua resposta apontando elementos que têm uma relação importante com tal situação.

\section{Procedimentos}

Os dados foram coletados via Survey (on-line). O procedimento de contato e solicitação da participação das pessoas ocorreu por meio das redes sociais e e-mail. O questionário do estudo ficou disponível on-line entre os dias 15 e 25 de julho de 2014. A presente proposta de pesquisa foi aprovada pelo Comitê de Ética em Pesquisas com Seres Humanos da Universidade Federal de Roraima (Protocolo n. 659.604). Todos os princípios éticos foram respeitados, em consonância com a Resolução CNS n. 466/12, garantindo aos respondentes o anonimato de suas respostas, a participação voluntária e a possibilidade de declínio do preenchimento em qualquer momento sem prejuízo.

\section{Análise dos dados}

Os bancos textuais foram analisados por meio do software de análises de dados textuais Iramuteq (Interface de R pour analyses Multidimensionnelles de Textes et de Questionnaires, versão 0.7 alpha 2) (Ratinaud, 2009), hospedado no ambiente $R$ (R Development Core Team, 2015; versão 3.2.2). Após a criação do corpus textual de todos os sujeitos da pesquisa, cada um representando uma Unidade de Contexto Inicial (UCI), foi realizada uma análise de Classificação Hierárquica Descendente (CHD). Tal procedimento classificou os segmentos de texto consoante seus respectivos vocabulários, com base na frequência e qui-quadrado $\left(\chi^{2}\right)$, permitindo a criação de classes de Unidades de Contexto Elementares (UCE) com as palavras que apresentam vocabulário similar entre si e distinto das UCE das demais classes (Camargo, 2005). Uma vez criadas as classes de UCE, elas foram nomeadas e descritas.

\section{Resultados}

Esta seção está organizada em dois blocos de resultados. Em um primeiro momento, constam os que correspondem à primeira questão aberta, sobre a adoção de criança por casais heterossexuais estéreis (corpus 1). Em seguida, são expostos os resultados acerca da adoção de criança por casais homossexuais (corpus 2).

\section{Adoção de criança por casais heterossexuais estéreis (corpus 1)}

A CHD do corpus 1, obtida a partir das respostas dos sujeitos, foi formada por 484 UCI. O corpus foi dividido em 636 UCE, das quais $88,5 \%$ foram consideradas na CHD, sendo analisadas 21.823 palavras com média de 
30,0 em termos de ocorrências. O corpus 1 se dividiu em cinco classes de segmentos de textos e foram descritas apenas aquelas palavras cujos escores de qui-quadrado eram mais altos, cinco vezes maior que o valor mínimo $\left(\chi^{2} \geq 19,20\right)$, acarretando, assim, menor margem de erro em cada associação da palavra com sua classe respectiva. No dendograma da Figura 1, é indicada a frequência média de cada palavra, seguida do valor do qui-quadrado.

\begin{tabular}{|c|c|c|c|c|c|c|c|c|c|c|c|c|c|c|}
\hline & & & \multicolumn{6}{|c|}{$\longmapsto$} & \multicolumn{6}{|c|}{$\longrightarrow$} \\
\hline \multicolumn{3}{|c|}{$\begin{array}{c}\text { Classe 5 } \\
\mathbf{1 2 7} \text { UCEs } \\
20,0 \% \\
\text { Agravantes }\end{array}$} & \multicolumn{3}{|c|}{\begin{tabular}{|c|} 
Classe 2 \\
103 UCEs \\
$16,1 \%$ \\
Desenvolvimento Normal
\end{tabular}} & \multicolumn{3}{|c|}{$\begin{array}{c}\text { Classe 1 } \\
\text { 119UCEs } \\
18,8 \% \\
\text { Educação }\end{array}$} & \multicolumn{3}{|c|}{$\begin{array}{c}\text { Classe 4 } \\
\text { 121UCEs } \\
19,0 \% \\
\text { Solidariedade }\end{array}$} & \multicolumn{3}{|c|}{$\begin{array}{c}\text { Classe } 3 \\
\text { 166 UCEs } \\
26,1 \% \\
\text { Responsabilidade }\end{array}$} \\
\hline Palavra & f & $\chi^{2}$ & Palavra & & $\chi^{2}$ & Palavra & f & $\chi^{2}$ & Palavra & & $\chi^{2}$ & Palavra & & $\chi^{2}$ \\
\hline Fator & 24 & 36,7 & Normal & 112 & 49,5 & Educação & 63 & 66,8 & Amor & 2027 & 70,6 & Filho & 254 & 52,9 \\
\hline Personalidade & 12 & 36,5 & Adequado & 17 & 41,0 & Crescer & 26 & 64,2 & Ato & 51 & 63,6 & Casal & 194 & 51,7 \\
\hline Apresentar & 9 & 36,5 & Estrutura & 12 & 31,1 & Respeito & 40 & 50,1 & Válido & 42 & 39,1 & Adotar & 251 & 43,1 \\
\hline Abandono & 10 & 32,4 & Base & 10 & 30,4 & Dedicação & 8 & 35,0 & Suprir & 10 & 33,2 & Condição & 81 & 38,6 \\
\hline Trauma & 12 & 30,7 & Ajustar & 16 & 28,8 & Limite & 8 & 24,3 & Atenção & 29 & 22,6 & Dar & 78 & 35,0 \\
\hline Fato & 31 & 27,2 & Aspecto & 14 & 26,3 & Equilibrado & 8 & 21,8 & Solidariedade & 10 & 20,4 & Criar & 74 & 30,1 \\
\hline Sofrer & 9 & 27,1 & Famíliar & 25 & 22,7 & Qualidade & 17 & 21,9 & & & & Dever & 176 & 25,8 \\
\hline Processo & 15 & 26,9 & Desenvolvimento & 218 & 22,5 & Dignidade & 5 & 21,8 & & & & Gerar & 26 & 23,6 \\
\hline História & 8 & 24,2 & Sexualidade & 10 & 21,6 & Ensinar & 5 & 20,9 & & & & Achar & 139 & 20,6 \\
\hline Influência & 6 & 24,2 & Fornecer & & 20,8 & Mostrar & 11 & 20,8 & & & & Heterossexua & 117 & 20,4 \\
\hline Questão & 17 & 23,7 & Incentivo & 4 & 20,8 & Receber & 7 & 20,2 & & & & & & \\
\hline Lidar & 12 & 22,9 & & & & Sociedade & 20 & 19,7 & & & & & & \\
\hline Origem & 11 & 22,9 & & & & Importar & 18 & 19,5 & & & & & & \\
\hline Influeciar & 10 & 22,9 & & & & & & & & & & & & \\
\hline Adotivo & 52 & 20,3 & & & & & & & & & & & & \\
\hline Menor & 5 & 20,2 & & & & & & & & & & & & \\
\hline Interferir & 5 & 20,2 & & & & & & & & & & & & \\
\hline
\end{tabular}

\section{Figura 1}

Dendograma da classificação hierárquica descendente do corpus 1 .

Inicialmente, o corpus 1 foi dividido ( $1^{\text {a }}$ partição) em dois subcorporas: de um lado, o da classe 5 e do outro, das classes 1, 2, 3 e 4. Num segundo momento, o primeiro subcorpora foi dividido em dois ( $2^{\mathrm{a}}$ partição), originando, de um lado, as classes 1, "Educação", e 2, "Desenvolvimento normal”; e de outro lado, as classes 3, "Responsabilidade", e 4, "Solidariedade" (3a partição). Numa quarta subdivisão, o terceiro subcorpora (4a partição) originou a classe 5, "Agravantes", em oposição às demais classes. A seguir, os conteúdos de tais classes são descritos.

A classe 1, Educação (18,8\% das UCE), aponta a educação como um elemento importante que os casais adotantes devem proporcionar aos filhos. Aspectos como o respeito, assim como a dedicação do casal adotante, são indicados como importantes. Além disso, a expressão "educação" abrange questões como as regras da vida diária e limites voltados ao comportamento das crianças. Esse aspecto é ilustrado no seguinte trecho de relato de um respondente: "Tudo o que uma criança precisa é de amor, respeito e educação. Às vezes não importa quem de fato é res- ponsável por essa educação, seja pai, mãe, biológico ou adotivo, como tia, avó; contanto que ela receba" (Sujeito 103, gênero masculino, 18 anos, ensino superior incompleto, homossexual, católico).

A classe 2, Desenvolvimento normal $(16,1 \%$ das UCE), abrange aspectos do desenvolvimento das crianças alvo de adoção. Os respondentes indicam que o desenvolvimento da criança adotada será normal, da mesma forma que ocorre com filhos biológicos. No entanto, o desenvolvimento das crianças é condicionado a um lar e ambiente adequados, tal como indica a ilustração da presente classe: “Toda criança poderá ter um desenvolvimento normal desde que os pais possam oferecer o ambiente e as condições adequadas para tal' (Sujeito 197, gênero masculino, 22 anos, homossexual, ensino médio completo, católico).

O contexto da classe 3, Responsabilidade (26,1\% das UCE), trata da adoção por casal heterossexual que possui tal intenção enquanto uma responsabilidade deles. Além disso, tal ato é tido como ação a ser encorajada, com a ressalva da exigência de que eles demonstrem condições favoráveis para cuidar da criança, 
como indicam os seguintes excertos: "Acredito ser uma alternativa que deveria ser incentivada. Uma criança adotada tem um desenvolvimento comum ao de uma criança gerada pelos pais" (Sujeito 037, gênero feminino, 21 anos, bissexual, ensino superior incompleto, espírita); "Acho que se é um desejo profundo por parte do casal, devem adotar" (Sujeito 039, gênero feminino, 26 anos, heterossexual, pós-graduação, católico).

A classe 4, Solidariedade (19,0\% das UCE), compreende a adoção por casal heterossexual como um ato de solidariedade, uma ação de caráter nobre, positiva e válida e, ainda, como um oferecimento da possibilidade de dar e receber amor mutuamente, no sentido de suprir as demandas das partes envolvidas nesse processo. $\mathrm{O}$ fragmento a seguir ilustra tal classe: "Bastante louvável e deveria ser incentivado, pois ainda vivemos em um país onde muitas crianças não têm um lar e dar a elas essa oportunidade é um gesto de amor e solidariedade" (Sujeito 49, gênero feminino, 49 anos, heterossexual, pós-graduação, espírita).

A classe 5, Agravantes (20,0\% das UCE), surge em oposição às demais por se referir à ocorrência de possíveis problemas psicológicos que possam impactar no desenvolvimento das crianças adotadas. Tais problemas são associados às situações de abandono sofridas por essas crianças, bem como à condição de orfandade. Ainda, os respondentes salientam que diversos fatores, como a personalidade e a idade da criança, podem influenciar na forma com que ela lidaria com possíveis dificuldades. O seguinte fragmento ilustra tal contexto: "Provavelmente, se for adotada cedo, não acredito que seu desenvolvimento seja diverso do que o de outras crianças. Em caso negativo, provavelmente existem alguns traumas herdados da situação de abandono ou perda dos familiares" (Sujeito 013, gênero masculino, 26 anos, bissexual, ensino superior incompleto, ateu).

A seguir, são apresentados os resultados do corpus 2 , opiniões sobre adoção por homossexuais.

\section{Adoção de criança por casais homossexuais (corpus 2)}

A CHD do corpus 2 obtida a partir das respostas dos sujeitos foi formada por 484 UCI. O corpus foi dividido em 882 UCE, das quais $89,0 \%$ foram consideradas na CHD, sendo analisadas 31.349 palavras com média de 32,0 em termos de ocorrências. O corpus se dividiu em cinco classes de segmentos de textos e foram descritas apenas aquelas palavras cujos escores de qui-quadrado eram mais altos, cinco vezes maior que o valor mínimo $\left(\chi^{2} \geq 19,20\right)$, para trabalhar com menor margem de erro em cada associação da palavra com sua respectiva classe. Na Figura 2, apresenta-se o dendograma em que são indicadas a frequência média de cada palavra seguida do valor do qui-quadrado.

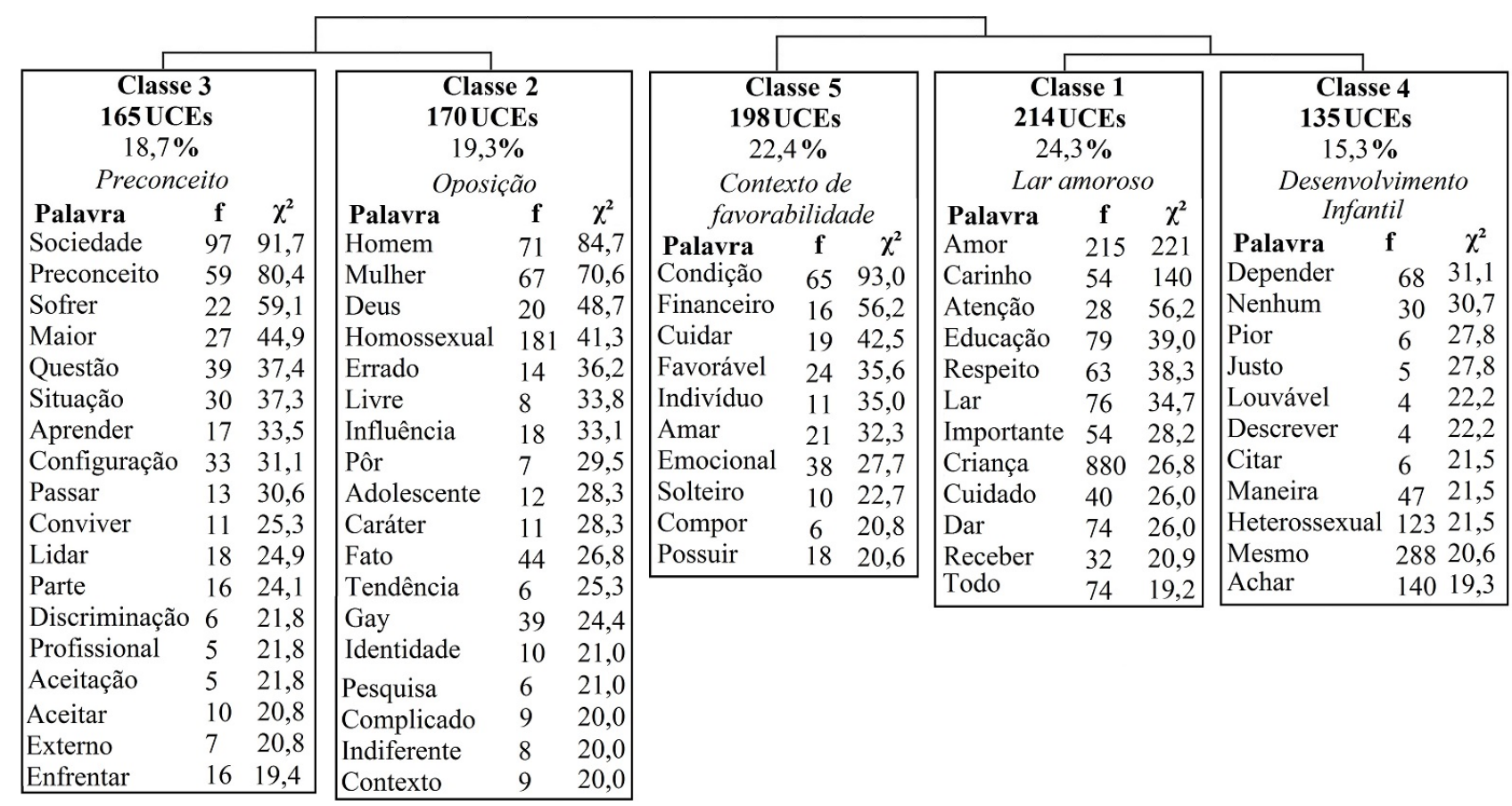

Figura 2

Dendograma da classificação hierárquica descendente do corpus 2. 
Inicialmente, o corpus 2 foi dividido ( $1^{\text {a }}$ partição) em dois subcorpora: de um lado, o das classes 2 e 3 e do outro, o das classes 1, 4 e 5 . Num segundo momento, o primeiro subcorpora foi dividido em dois ( $2^{\mathrm{a}}$ partição), originando, de um lado, a classe 5 , "Contexto de favorabilidade", e de outro, as classes 1, "Lar amoroso", e 4, "Desenvolvimento infantil". Em um terceiro momento, o segundo subcorpus foi dividido em dois ( $3^{a}$ partição): de um lado, o da classe 2, "Oposição", e de outro, o da classe 3, "Preconceito", com estas em oposição às demais classes (Figura 2).

A classe 1, Lar amoroso (24,3\% das UCE), abrange características necessárias no que tange ao lar onde a criança irá crescer, como amor, carinho, respeito e educação. Nesse sentido, tal lar deve possibilitar o desenvolvimento afetivo e cognitivo da criança, e deve ser, ainda, um ambiente equilibrado. Esta classe prioriza aspectos afetivos e de suporte em termos emocionais para as crianças adotadas, como pode ser observado no seguinte trecho: "Acredito que caso a criança seja criada em um lar em que se valorize o afeto, a atenção e a imposição de limites, ela irá se desenvolver normalmente" (Sujeito 337, gênero feminino, 22 anos, homossexual, ensino superior incompleto, agnóstico).

No contexto da classe 2, Oposição (19,3\% das UCE), as respostas dos sujeitos ressaltam um posicionamento contrário à adoção por casal homossexual. Os respondentes justificam seus argumentos baseando-se em princípios religiosos e morais ao enfatizarem que Deus criou o homem e a mulher para a reprodução biológica, assim como que qualquer configuração distinta dessa não constitui uma família legítima. O seguinte excerto exemplifica tal cenário: "Péssima opção. Não deve ser incentivado. Muito provavelmente terão problemas psicológicos. Foge totalmente dos papéis do homem e da mulher. A família tradicional é a única que é capaz de gerar pessoas" (Sujeito 442, gênero masculino, 36 anos, heterossexual, pós-graduação, católico).

A classe 3, Preconceito (18,7\% das UCE), enfatiza uma situação conflituosa por parte de crianças adotadas por casais homossexuais: o preconceito da sociedade. Nesse contexto, o preconceito é concebido como algo que afeta negativamente uma criança em tal configuração familiar, no sentido de que ela deverá aprender a lidar satisfatoriamente com ocasiões sociais nas quais seja questionada por ter pais do mesmo gênero. $\mathrm{O}$ trecho a seguir ilustra o contexto da presente classe: "O problema maior é em relação à própria sociedade e não ao modo como essas crian- ças serão criadas, pois o preconceito que vem de fora pode atrapalhar o desenvolvimento dessas crianças" (Sujeito 075, gênero feminino, 19 anos, heterossexual, ensino superior incompleto, católica).

A classe 4, Desenvolvimento infantil $(15,3 \%$ das UCE), diz respeito ao desenvolvimento das crianças adotadas por casais homossexuais. Nela, o desenvolvimento infantil considerado saudável subordina-se a questões que podem ou não gerar prejuízos aos filhos adotivos, como o ambiente, o apoio de familiares etc. Entretanto, tal questão é condicionada à transmissão de determinados padrões valorativos a priori. Expõe-se um excerto ilustrativo da presente classe: "Dependerá da educação e valores que serão passados para a criança. Além disso, o bom desenvolvimento dependerá de como o casal homossexual vai ajudar a criança a enfrentar possiveis preconceitos" (Sujeito 102, gênero feminino, 54 anos, bissexual, pós-graduação, espírita).

Por fim, a classe 5, Contexto de favorabilidade (22,4\% das UCE), sugere uma aceitação em relação à adoção de crianças por casais homossexuais, no entanto, estabelece condições que devem ser atendidas. Tais requisitos são referentes a aspectos financeiros, emocionais e psicológicos do casal adotante. Ainda, nessa classe, os sujeitos explicam que uma família não é necessariamente composta por um pai e uma mãe e que a orientação sexual dos pais não traz prejuízos à criança. Cita-se um fragmento que ilustra tal contexto: "Sou a favor. Se for por um casal com condições emocionais, financeiras e que deseje adotar, acredito que terá um desenvolvimento normal, igual a de um filho de um casal heterossexual" (Sujeito 411, gênero feminino, 20 anos, heterossexual, ensino superior incompleto, agnóstico).

\section{Discussão}

O presente estudo teve como objetivo conhecer as opiniões de uma amostra brasileira acerca da adoção por homossexuais. Mais especificamente, objetivou-se contrastar tais opiniões, considerando, também, pretendentes à adoção que fossem heterossexuais estéreis. Sendo assim, este estudo foi levado a cabo em dois momentos principais, concentrando atenção em cada um dos arranjos familiares investigados nessa oportunidade. Os resultados apontaram diferentes padrões de aceitação e oposição em função do tipo de configuração do arranjo parental da família adotante. Em resumo, a adoção de crianças por casais homossexuais obteve maior padrão de oposição, segundo a opinião dos participantes deste 
estudo, e, por sua vez, os casais heterossexuais estéreis foram avaliados com maior aceitação. Discute-se, pormenorizadamente, esses resultados, a seguir.

Inicialmente, cabe ponderar que no cenário brasileiro atual, a homossexualidade apresenta-se como uma das categorias que mais têm gerado debates e diferentes posicionamentos, em razão de confrontar o modelo tradicional de família nuclear, que historicamente se relaciona às noções de família e sexualidade (Cecílio, Scorsolini-Comin, \& Santos, 2013). Tais questões se acirram, mais especificamente, no contexto da possibilidade de constituição da conjugalidade (união entre pessoas do mesmo gênero) e, sobretudo, no exercício da parentalidade (quando casais homossexuais constituem família por meio da filiação adotiva). Tendo em vista que a adoção é possível em múltiplas formas em diferentes contextos, decidiu-se confrontar a opinião de pessoas frente à adoção por casais heterossexuais inférteis, que constitui um dos principais tipos de demandas observadas para a adoção (outros exemplos são: casais com filhos biológicos, casais na meia idade e indivíduos solteiros; Schettini, Amazonas, \& Dias, 2006). Os respondentes emitiram opiniões sobre a adoção de crianças em dois cenários: por casais heterossexuais estéreis e por casais homossexuais.

Considerando o contexto dos casais heterossexuais estéreis, os resultados apontaram que a adoção é concebida como de inteira responsabilidade do casal adotante, demandando que haja um real desejo na questão. Tal preocupação por parte dos respondentes é plausível, à medida que há necessidade de planejamento, conhecimento das motivações, desejos e riscos que envolvem um processo de adoção (Weber, 1999). Ainda, tal questão associa-se a outro elemento observado: a concepção de adoção como um ato de solidariedade. Sob essa ótica, tal concepção pode se associar a um caráter assistencial ou filantrópico com objetivo último de remediar feridas subjetivas dos adotantes (Schettini et al., 2006). Em certa medida, tais apreensões podem resultar da herança cultural da adoção no Brasil, que se faz presente desde a época da colonização, quando consistia em um ato de caridade cristã (Paiva, 2004).

Ademais, identificaram-se exigências que os casais, nas duas condições analisadas, deveriam cumprir em um processo de adoção. No caso do arranjo heterossexual incapaz biologicamente de gerar filhos, os dados mostraram que a única exigência para a ado- ção se refere à capacidade dos pais adotivos de oferecerem educação à criança adotada. Na situação dos casais homossexuais, além do fator educação, há uma ênfase na necessidade de afeto, ou seja, de que um "lar amoroso" seja proporcionado à criança. Adicionalmente, há referências que sugerem a importância de ser um "ambiente equilibrado", fato que se associa a condições financeiras adequadas do casal. Entretanto, os dados apontam para elementos intrapessoais, que ressaltam a exigência de o casal homossexual apresentar estados emocionais e psicológicos considerados equilibrados. Estudos oriundos de outros contextos também encontraram tais elementos. Em estudo de Morse, McLaren e McLachlan (2008), observou-se que a concepção das pessoas entrevistadas, amostra de sujeitos australianos heterossexuais, concebia os casais homossexuais como emocionalmente instáveis, irresponsáveis, insensíveis e não carinhosos. Ademais, os participantes acreditavam que a parentalidade exercida por um casal formado por pessoas do mesmo gênero relacionava-se a efeitos prejudiciais à criança (Morse et al., 2008).

No que tange ao desenvolvimento de crianças adotadas, novamente, no arranjo heterossexual infértil, os respondentes vinculam o desenvolvimento normal delas a uma argumentação genérica, exigindo-se somente "condições adequadas". No arranjo homossexual, o desenvolvimento típico da criança está condicionado ao tipo de educação e aos valores transmitidos à criança. A ênfase dada a esses aspectos sugere que casais homossexuais, a priori, são considerados como não dotados de condições morais para adotar uma criança, conforme aponta Marmitt (1993). Efetivamente, a condenação moral compreende uma porção significativa das atitudes frente a gays e lésbicas (Massey, 2009). Em termos práticos, tal cenário focado em características individuais do casal adotante cria exigências em maior grau, no sentido de atestar um contexto suficientemente favorável que assegure um desenvolvimento considerado saudável para a criança.

Situações potencialmente estressoras para as crianças sob condição de adoção em ambos os arranjos foram identificadas nas classes "Agravantes" e "Preconceito". Na primeira, relacionada ao arranjo heterossexual, os sujeitos discorreram sobre os traumas que uma criança adotada vivencia, em razão de sua situação de abandono, indicando maior probabilidade de haver desenvolvimento normal caso a criança seja adotada em idade precoce. Tais resultados corroboram estudos 
anteriores (Mariano, 2004; Weber, 2003), apontando receios frente às adoções tardias, fundamentados no estigma de que crianças de idade avançada trariam consigo maus hábitos das famílias de origem, seja por convivência ou herança biológica, ou ainda por experiências em abrigos, fato que poderia criar dificuldades no estabelecimento de vínculos da criança com uma nova família (Schettini et al., 2006).

Em relação aos casais homossexuais, o fator estressor enfatizado pelos respondentes foi o impacto do preconceito oriundo da sociedade nas crianças inseridas nesse arranjo. Em termos práticos, essa espécie de discurso predispõe a não aceitação, por parte da sociedade, de famílias compostas por pessoas do mesmo gênero, exigindo-se que os gays e lésbicas se adaptem às normas socialmente estabelecidas, baseadas em argumentos heterossexistas (Clarke, 2001). De fato, como demonstra o estudo desenvolvido por Tombolato, Maia, Uziel e Santos (2018) acerca das vivências e manifestações de preconceito e discriminação no cotidiano de cinco casais homossexuais com filhos, os casais enfrentavam dificuldades no cotidiano em razão de desafiarem as convenções sociais e estereótipos associados ao gênero. Entretanto, de igual modo, os casais entrevistados mostraram exercer um papel de protagonismo social através da concretização dos projetos de conjugalidade e, por extensão, de maternidade e paternidade frente ao cenário heteronormativo da sociedade. Ainda, tais autores asseveram que discussões em torno da adoção homoparental são importantes por contribuírem para a expansão do conceito de família, tendo em vista que anos atrás tais questões sequer eram socialmente debatidas (Tombolato et al., 2018).

Por outro lado, de igual modo, os resultados observados indicaram posicionamentos explicitamente contrários à adoção homoparental, mais especificamente presentes no conteúdo da classe "Oposição". As argumentações identificadas se baseiam claramente em postulados religiosos acerca da família nuclear e dos papéis de gênero socialmente estabelecidos. Essas justificativas ancoram-se na categoria de preconceito flagrante - manifestado por meio da alta rejeição à intimidade e da alta expressividade de emoções negativas (Pettigrew \& Meertens, 1995) - e têm como suposição que a causa da homossexualidade assenta-se em crenças de natureza religiosa - como a da tendência pecaminosa da homossexualidade - e de natureza ético-moral - como a da tendência dos homossexuais para a violação dos valores morais e tradicionais (Lacerda, Pereira, \& Camino, 2002). No Brasil, a dominância de tais crenças sobre as causas da homossexualidade já foi empiricamente comprovada (Pereira, Torres, Pereira, \& Falcão, 2011); ademais, de igual modo, há evidências de que as crenças de bases religiosas e moralistas predizem maior suporte à discriminação, manifestada em situações de oposição ao casamento e à adoção de crianças por casais homoafetivos (Pereira et al., 2013).

De fato, conforme consistentemente observado na literatura, os denominados valores familiares e concepções conservadoras sobre os papéis de gênero configuram-se como fortes subsídios à rejeição ao exercício da parentalidade por homossexuais em função da busca pela manutenção dos valores tradicionais, o que consiste em heterossexismo (Whitley, 2001). Dentro desse panorama, ainda que se saiba que a expressão do heterossexismo tenha gradualmente se transmutado para o denominado preconceito sutil ou moderno (Augoustinos, 2009; Morrison, Morrison, \& Franklin, 2009), caracterizado por baixa rejeição à intimidade e baixa expressividade de emoções negativas (Pettigrew \& Meertens, 1995), no Brasil, como já relatado anteriormente, ainda perdura um cenário de preconceito explícito.

Tais aspectos podem ser mais bem elucidados pela ampliação trazida a partir das normas sociais de padrão hetero-cis-normativo (ou cisheteronormatividade). Entende-se por cisheteronormatividade, nesta oportunidade, todo e qualquer instrumento normativo de papéis de gênero, concebido de maneira essencialista, ou seja, se tratam de normas binárias que referendam a feminilidade/masculinidade a partir de determinantes biológicos. Tais normas incidem na sociedade produzindo identidades sexuais impedidas de "possibilidades de derivação passível de apropriação pessoal, social, cultural e histórica do feminino e do masculino, por pessoas de ambos os sexos" (Lionço \& Diniz, 2008, p. 310).

De forma concreta, embora as atitudes sociais sobre gays e lésbicas tenham se tornado mais favoráveis ao longo do tempo, desde o advento dos movimentos pelos direitos dos homossexuais nas décadas de 1970 e 1980, essa maior tolerância não se estendeu completamente à questão da parentalidade homossexual (Frias-Navarro, Monterde-i-Bort, Barrientos-Delgado, Badenes-Ribera, \& Cardenas-Castro, 2014), como demonstram os presentes achados, que evidenciam o padrão cisheteronormativo dos partici- 
pantes deste estudo, quando se contrasta o padrão de resposta dos sujeitos frente a arranjos heterossexuais inférteis. Claramente, tal cenário aponta para a necessidade de legislações expressas, no contexto brasileiro, que disponham sobre a matéria, já que elas podem ser entendidas como um fator de proteção social aos grupos sexuais minorizados, como já observado em estudos que investigaram o papel de legislação específica (Rodrigues \& Brito, 2018; Silva, 2018). Assim, a lei, entendida como uma variável institucional, pode impactar positivamente nas crenças dos indivíduos frente ao fenômeno da adoção homoparental, em função da importância da influência de elementos contextuais nas normas individuais (Scheepers et al., 2002).

Os objetivos do presente estudo foram satisfatoriamente alcançados. Em geral, a adoção de crianças por casais homossexuais obteve maior padrão de oposição e, por sua vez, os casais heterossexuais estéreis foram avaliados com maior aceitação, reforçando o padrão cisheteronormativo dos participantes deste estudo, quando se contrasta o padrão de resposta dos sujeitos frente a arranjos heterossexuais no contexto da infertilidade. Contudo, há potenciais limitações no estudo. Deve-se ter em conta a possível influência do viés de desejabilidade social, bem como do meio utilizado para coletar as respostas (on-line). Tais aspectos podem ter gerado distorções no autorrelato, que podem ter sido voltados a direções socialmente desejáveis, tendo em vista que os pesquisadores detêm pouco controle experimental do momento em que os sujeitos respondem a instrumentos de coleta de dados dessa natureza. Sendo assim, espera-se que que estudos futuros sejam levados a cabo, a partir do que foi levantado nesta oportunidade.

Nesse sentido, seria interessante conhecer também, por exemplo, as opiniões de crianças que convivem no contexto escolar com crianças de famílias para além do modelo nuclear, assim como contar com estudos longitudinais com crianças adotadas em diferentes arranjos familiares; tais estudos podem fornecer informações complementares ao que foi tratado nesta oportunidade, sobretudo quanto à perspectiva infantil. Além disso, igualmente relevantes seriam estudos transculturais que levassem em conta diferentes países com legislações pró e contra a regulamentação da adoção homoparental no contexto latino-americano. Acrescenta-se ainda, nesta oportunidade, visando ampliar o que foi tratado no presente estudo, a pertinência de desenvolver estudos que comparem opiniões de pessoas com distintas orientações sexuais e/ou identidades de gêneros, incluindo outras variáveis como proximidade/distanciamento com grupos sexuais minorizados, nível de religiosidade e preconceito sexual, a fim de ampliar o escopo de discussão sobre a temática no Brasil. Por fim, tendo em vista a recente decisão do STF de criminalização da lgbtfobia e sua equiparação ao crime de racismo, o presente estudo aponta que apesar dos avanços jurídicos, a situação dos grupos sexuais minorizados ainda é bastante crítica e marcada pelo preconceito e pela discriminação.

\section{Referências}

Aboim, S. (2007). Clivagens e continuidades de género face aos valores da vida familiar em Portugal e noutros países europeus. In K. Wall, \& L. Amâncio (Orgs.), Família e Género em Portugal e na Europa (pp. 35-91). ICS.

Altemeyer, B. (1998). The other "authoritarian personality". In M. Zanna (Ed.), Advances in experimental social psychology (Vol. 30, pp. 47-92). Academic Press.

Appell, A. R. (2001). Lesbian and gay adoption. Adoption Quarterly, 4(3), 75-86. https://doi.org/10.1300/ J145v04n03_05

Araújo, L. F., Oliveira, J. S. C., Sousa, V. C., \& Castanha, A. R. (2007). Adoção de crianças por casais homoafetivos: Um estudo comparativo entre universitários de Direito e de Psicologia. Psicologia \& Sociedade, 19(2), 95-102. https://doi.org/10.1590/S0102-71822007000200013

Augoustinos, M. (2009). Racism(s): One or many? International Journal of Psychology, 44(1), 43-45. https://doi. org/10.1080/00207590802057944

Azevedo, A. V. (2011). Estatuto da família de fato. Atlas.

Baranoski, M. C. R. (2016). A adoção em relações homoafetivas. Editora UEPG.

Berkowitz, D., \& Marsiglio, W. (2007). Gay men: Negotiating procreative, father, and family identities. Journal of Marriage and Family, 69(2), 366-381. https://doi.org/10.1111/j.1741-3737.2007.00371.x 
Brodzinsky, D. M., Patterson, C. J., \& Vaziri, M. (2002). Adoption agency perspectives on lesbian and gay prospective parents: A national study. Adoption Quarterly, 5(3), 5-23. https://doi.org/10.1300/J145v05n03_02

Camargo, B.V. (2005). Alceste: Um programa informático de análise quantitativa de dados textuais. In A. S. P. Moreira, B. V. Camargo, J. V. Jesuíno, \& S. M. Nóbrega (Orgs.), Perspectivas teórico-metodológicas em representações sociais (pp. 511-539). Editora UFPB.

Cecílio, M. S., Scorsolini-Comin, F., \& Santos, M. A. (2013). Produção científica sobre adoção por casais homossexuais no contexto brasileiro. Estudos de Psicologia, 18(3), 507-516. https://doi.org/10.1590/S1413-294X2013000300011

Clarke, V. (2001). What about the children? Arguments against lesbian and gay parenting. Women's Studies International Forum, 24(5), 555-570. https://doi.org/10.1016/S0277-5395(01)00193-5

Daniliauskas, M. (2011). Relações de gênero, diversidade sexual e políticas públicas de educação: Uma análise do Programa Brasil sem Homofobia [Dissertação de mestrado, Universidade de São Paulo]. Biblioteca Digital de Teses e Dissertações da USP. https:/ /www.teses.usp.br/teses/disponiveis/48/48134/tde-06072011-095913/pt-br.php

EOS Gallup Europe. (2003). Homosexual marriage, child adoption by homosexual couples: Is the public ready? [Comunicado de imprensa]. https://www.rklambda.at/archiv/dokumente/news_2003/News-PA-031015Gallup-Umfrage-Text.pdf

Falcão, L. C. (2004). Adoção de crianças por homossexuais: Crenças e formas de preconceito [Dissertação de mestrado, Pontifícia Universidade Católica de Goiás]. Biblioteca Digital de Teses e Dissertações da PUC-Goiás. http://tede2. pucgoias.edu.br:8080/handle/tede/1931

Fiuza, M. (2015). Pela primeira vez, STF reconhece direito de adoção por casais homossexuais. JusBrasil. http:// moemafiuza.jusbrasil.com.br/noticias/175556906/pela-primeira-vez-stfreconhece-direito-de-adocao-porcasais-homossexuais?ref=topic_feed

Freires, L. A. (2015). Atitudes frente a homoparentalidade: Uma explicação a partir de variáveis explícitas e implícitas [Tese de doutorado, Universidade Federal da Paraíba]. Repositório digital da UFPB. https://repositorio.ufpb.br/ jspui/bitstream/tede/7521/2/arquivototal.pdf

Frias-Navarro, D., Monterde-i-Bort, H., Barrientos-Delgado, J., Badenes-Ribera, L., \& Cardenas-Castro, M. (2014). Beliefs about children's adjustment in same-sex families: Spanish and Chilean university students. The Spanish Journal of Psychology, 17, 1-9. https://doi.org/10.1017/sjp.2014.5

Frost, D. M., \& Meyer, I. H. (2009). Internalized homophobia and relationship quality among lesbians, gay men, and bisexuals. Journal of Counseling Psychology, 56(1), 97-109. https://doi.org/10.1037/a0012844

Gates, G. J., Badgett, M. V. L., Macomber, J. E., \& Chambers, K. (2007). Adoption and foster care by gay and lesbian parents in the United States. The Williams Institute.

Gato, J., \& Fontaine, A. M. (2014). Homoparentalidade no masculino: Uma revisão da literatura. Psicologia \& Sociedade, 26(2), 312-322. https://dx.doi.org/10.1590/S0102-71822014000200008

Golombok, S. (2015). Modern families: Parents and children in new family forms. Cambridge University.

Grupo Gay da Bahia. (2016). Assassinato de homossexuais (LGBT) no Brasil: Relatório 2015 [Relatório]. http:// pt.calameo.com/read/0046502188e8a65b8c3e2

Grupo Gay da Bahia. (2017). Pessoas LGBT mortas no Brasil: Relatório 2017 [Relatório]. https://homofobiamata. files.wordpress.com/2017/12/relatorio-2081.pdf

Lacerda, M., Pereira, C., \& Camino, L. (2002). Um estudo sobre as formas de preconceito contra homossexuais na perspectiva das representações sociais. Psicologia: Reflexão e Crítica, 15(1), 165-178. https://doi.org/10.1590/ S0102-79722002000100018

Lionço, T., \& Diniz, D. (2008). Homofobia, Silêncio e Naturalização: Por uma narrativa da diversidade sexual. Psicologia Política, 16(8), 307-324.

Lomando, E., Wagner, A., \& Gonçalves, J. (2011). Coesão, adaptabilidade e rede social no relacionamento conjugal homossexual. Psicologia: Teoria e Prática, 13(3), 96-109.

Machin, R. (2016). Homoparentalidade e adoção: (Re)afirmando seu lugar como família. Psicologia \& Sociedade, 28(2), 350-359. https://doi.org/10.1590/1807-03102016v28n2p350 
Mariano, F. N. (2004). O cenário jurídico: A análise de processos de adoção no município de Ribeirão Preto (19912000) [Dissertação de mestrado]. Universidade de São Paulo.

Marmitt, A. (1993). Adoção. Aide.

Massey, S. G. (2009). Polymorphous prejudice: Liberating the measurement of heterosexuals' attitudes toward lesbians and gay men. Journal of Homosexuality, 56(2), 147-172. https://doi.org/10.1080/00918360802623131

Mello, L. (2006). Familismo (anti)homossexual e regulação da cidadania no Brasil. Estudos feministas, 14(2), 497-508. https://doi.org/10.1590/S0104-026X2006000200010

Morrison, M. A., Morrison T. G., \& Franklin R. (2009). Modern and old-fashioned homonegativity among samples of Canadian and American university students. Journal of Cross-Cultural Psychology, 40(4), 523-42. https:// doi.org/10.1177/0022022109335053

Morse, C. N., McLaren, S., \& McLachlan, A. J. (2008). The attitudes of Australian heterosexuals toward same-sex parents. Journal of GLBT Family Studies, 3(4), 425-455. https://doi.org/10.1300/J461v03n04_04

Mott, L. (2006). Homo-afetividade e direitos humanos. Estudos Feministas, 14(2), 509-521. https://doi.org/10.1590/ S0104-026X2006000200011

Paiva, L. D. (2004). Adoção: Significados e possibilidades. Casa do Psicólogo.

Patterson, C. J. (2006). Children of lesbian and gay parents. Current Directions in Psychological Science, 15(5), 241244. http://dx.doi.org/10.1111/j.1467-8721.2006.00444.x

Pereira, C. R, Torres, A. R. R., Pereira, A. S., \& Falcão, L (2011). Preconceito contra homossexuais e representações sociais da homossexualidade em seminaristas católicos e evangélicos. Psicologia: Teoria e Pesquisa, 27(1), 73-82. http://dx.doi.org/10.1590/S0102-37722011000100010

Pereira, C. R., Torres, A. R. R., Falcão, L., \& Pereira, A. S. (2013). O papel de representações sociais sobre a natureza da homossexualidade na oposição ao casamento civil e à adoção por famílias homoafetivas. Psicologia: Teoria e Pesquisa, 29(1), 79-89. http://dx.doi.org/10.1590/S0102-37722013000100010

Pettigrew, T. F., \& Meertens, R. W. (1995). Subtle and blatant prejudice in Western Europe. European Journal of Social Psychology, 25(1), 57-75. https://doi.org/10.1002/ejsp.2420250106

Power, J. J., Perlesz, A., Schofield, M. J., Pitts, M. K., Brown, R., McNair, R., Barrett, A., \& Bickerdike, A. (2010). Understanding resilience in same-sex parented families: The work, love, play study. BMC Public Health, 10(1), 1-10. https://doi.org/10.1186/1471-2458-10-115

R Development Core Team. (2015). R: A language and environment for statistical computing. https://cran.r-project. $\mathrm{org} / \mathrm{doc} / \mathrm{manuals} /$ fullrefman.pdf

Ramos, S., \& Carrara, S. (2006). A constituição da problemática da violência contra homossexuais: A articulação entre ativismo e academia na elaboração de políticas públicas. Physis: Revista de Saúde Coletiva, 16(2), 185-205. https://doi.org/10.1590/S0103-73312006000200004

Ratinaud, P. (2009). IRAMUTEQ: Interface de R pour les Analyses Multidimensionnelles de Textes et de Questionnaires [Computer software]. http://www.iramuteq.org

Rodrigues, A. D. R., \& Brito, E. S. D. (2018). Adoção por casais homoafetivos: Uma análise de decisões judiciais [Trabalho de conclusão de curso, Centro Universitário Toledo]. Repositório digital da UniToledo. https://bit. ly/3gXcXcC

Santos, J.V. O., Araújo, L. F., Negreiros, F., \& Cerqueira-Santos, E. (2018). Adoção de crianças por casais homossexuais: As representações sociais. Temas em Psicologia, 26(1), 139-152. https://doi.org/10.9788/tp2018.1-06pt

Scheepers, P., Te Grotenhuis, M., \& van der Slik, F. (2002). Education, religiosity and moral attitudes: Explaining cross-national effect differences. Sociology of Religion, 63(2), 157-176. https://doi.org/10.2307/3712563

Schettini, S. S. M., Amazonas, M. C. L. A., \& Dias, C. M. S. B. (2006). Famílias adotivas: Identidade e diferença. Psicologia em Estudo, 11(2), 285-293. https://dx.doi.org/10.1590/S1413-73722006000200007

Silva, S. G. D. S. (2018). Os entraves jurídicos na organização familiar homoafetiva e a legislação brasileira [Trabalho de conclusão de curso, Centro Universitário Tabosa de Almeida]. Repositório digital da Unita. http://repositorio. asces.edu.br/bitstream/123456789/1505/1/ARTIGO\%20S\%C3\%82MYLA\%20GABRIELA.pdf 
Takács, J., \& Szalma, I. (2014). A homoszexualitással kapcsolatos társadalmi attitűdök vizsgálata Magyarországon és Romániában [Examining social attitudes towards homosexuality in Hungary and Romania]. Erdélyi Társadalom, 12(1), 9-30. https://doi.org/10.17177/77171.140

Takács, J., Szalma, I., \& Bartus, T. (2016). Social attitudes toward adoption by same-sex couples in Europe. Archives of sexual behavior, 45(7), 1787-1798. https://doi.org/10.1007/s10508-016-0691-9

Tasker, F. (2013). Lesbian and gay parenting post-heterosexual divorce and separation. In A. E. Goldberg, \& K. R. Allen (Eds.), LGBT-parent families: Innovations in research and implications for practice (pp. 3-20). Springer.

Tombolato, M. A., Maia, A. C. B., Uziel, A. P., \& Santos, M. A. (2018). Prejudice and discrimination in the everyday life of same-sex couples raising children. Estudos de Psicologia, 35(1), 111-122. https://doi.org/10.1590/198202752018000100011

Uziel, A. P. (2007). Homossexualidade e adoção. Garamond.

van den Akker, H., van der Ploeg, R., \& Scheepers, P. (2013). Disapproval of homosexuality: Comparative research on individual and national determinants of disapproval of homosexuality in 20 European countries. International Journal of Public Opinion Research, 25(1), 64-86. https://doi.org/10.1093/ijpor/edr058

Weber, L. N. D. (1999). Aspectos psicológicos da adoção. Juruá.

Weber, L. N. D. (2003). Pais e filhos por adoção no Brasil. Juruá.

Whitley, B. E. (2001). Gender-role variables and attitudes toward homosexuality. Sex Roles, 45(11), 691-721. https:// doi.org/10.1023/A:1015640318045

\section{Leogildo Alves Freires}

Doutor em Psicologia Social pela Universidade Federal da Paraíba (UFPB). Professor Adjunto A do Instituto de Psicologia da Universidade Federal de Alagoas (UFAL), Maceió - AL. Brasil.

E-mail: leogildo.alves.freires@gmail.com

(1) https://orcid.org/0000-0001-5149-2648

\section{Gleidson Diego Lopes Loureto}

Doutor em Psicologia Social pela UFPB. Professor do curso de Psicologia do Centro Universitário de Patos (Unifip), Patos - PB. Brasil.

E-mail: diegoloureto.dl@gmail.com

(1) https://orcid.org/0000-0002-0889-6097

Alessandro Teixeira Rezende

Psicólogo e doutor em Psicologia Social pela UFPB. Professor do curso de Psicologia da Faculdade de Integração do Sertão (FIS), Serra Talhada - PE. Brasil.

E-mail: als_tx29@hotmail.com

(1) https://orcid.org/0000-0002-5381-2155

\section{Ana Karla da Silva Soares}

Doutora em Psicologia Social pela UFPB. Professora Adjunta A do curso de Psicologia na Universidade Federal do Mato Grosso do Sul (UFMS), Campo Grande - MS. Brasil.

E-mail: akssoares@gmail.com

(1) https://orcid.org/0000-0001-5306-4073

Endereço para correspondência:

Universidade Federal de Alagoas, Campus AC Simões, Instituto de Psicologia, Sala 5. Av. Lourival Melo Mota, s/n. CEP: 57072-970. Maceió - AL. Brasil. 
Psicologia: Ciência e Profissão 2021 v. 41 (n.spe 3), e216273,1-14.

Recebido 07/11/2018

Aceito 22/08/2019

Received 11/07/2018

Approved 08/22/2019

Recibido $07 / 11 / 2018$

Aceptado 22/08/2019

Como citar: Freires, L. A., Loureto, G. D. L., Rezende, A. T., \& Soares, A. K. S. (2021). Contrastando opiniões acerca da adoção de crianças por casais hétero e homossexuais. Psicologia: Ciência e Profissão, 41 (n.spe 3), 1-14.

https://doi.org/10.1590/1982-3703003216273

How to cite: Freires, L. A., Loureto, G. D. L., Rezende, A. T., \& Soares, A. K. S. (2021). Contrasting opinions about children adoption by heterosexual and homosexual couples. Psicologia: Ciência e Profissão, 41 (n.spe 3), 1-14. https://doi.org/10.1590/1982-3703003216273

Cómo citar: Freires, L. A., Loureto, G. D. L., Rezende, A. T., \& Soares, A. K. S. (2021). Contraste de opiniones sobre la adopción de niños por parejas hetero y homosexuales. Psicologia: Ciência e Profissão, 41 (n.spe 3), 1-14. https://doi.org/10.1590/1982-3703003216273 